\title{
Rekenmethodiek overlijdensschade nieuwe stijl compleet
}

\author{
Mr. C.C.J. de Koning en J. Laumen-de Valk*
}

\section{Inleiding}

In de zomer van 2014 heeft de Denktank Overlijdensschade de Notitie van de Denktank Overlijdensschade en de rapportage van het Nationaal Instituut voor Budgetvoorlichting (Nibud) uitgebracht. In 2015 heeft De Letselschade Raad de aanbevelingen van de Denktank Overlijdensschade overgenomen en verwerkt in De Letselschade Richtlijn Rekenmodel Overlijdensschade. Overlijdensschade wordt sinds de Richtlijn van kracht is vrijwel alleen nog volgens deze methodiek uit 2015 berekend.

Al bij het opstellen van de Notitie in 2014 was het besef aanwezig bij de Denktankleden dat op termijn uitbreiding van de rekenmethode nodig zou zijn, om ook recht te doen aan andere dan de traditionele tweeoudergezinnen. Maar om niet te veel in één keer overhoop te halen werd er in 2015 voor gekozen om de uitbreiding niet gelijk ter hand te nemen.

$\mathrm{Nu}$ er een paar jaar gerekend is volgens de nieuwe methode uit 2015, en deze breed geaccepteerd is door zowel de markt als de rechterlijke macht, ${ }^{1}$ was het tijd om alsnog te werken aan de uitbreiding van de rekenmethodiek naar andere gezinnen dan het traditionele tweeoudergezin. Ook omdat er vanuit 'de markt' steeds vaker werd gevraagd om de rekenmethode uit te breiden tot de niet-standaardsituaties. Onder supervisie van de Werkgroep Normering van De Letselschade Raad is de Denktank Overlijdensschade weer bij elkaar gekomen, zij het in afgeslankte vorm, kortweg Denktank 2.0.

\section{Rekenmethode in het kort}

Even een geheugensteuntje hoe de rekenregel van de methodiek overlijdensschade sinds 2015 in elkaar steekt.

\footnotetext{
Mr. C.C.J. de Koning is letselschadeadvocaat. J. Laumen-de Valk is rekenkundige en arbeidsdeskundige letselschade.

Auteurs schreven deze bijdrage namens de Denktank 2.0. De Denktank 2.0 bestaat uit: mevr. J. Laumen-de Valk (voorzitter), dhr. J. Apperloo, dhr. E.J. Bakker, mevr. I. van der Kolk, dhr. C.C.J. de Koning, dhr. M. Neeser, mevr. X. Waaijenberg-Laumen, mevr. I. van der Zalm, dhr. F. Zwarts en mevr. I. van der Zwet.

1. Er zijn ons geen uitspraken bekend waarin de methode is verworpen Sinds 2015 zijn vrijwel alle overlijdensschades volgens de Denktankmethode afgewikkeld. In veel van deze zaken diende de vaststellingsovereenkomst vanwege de aanwezigheid van minderjarige kinderen aan de kantonrechter ter goedkeuring te worden voorgelegd. Ons zijn geen gevallen bekend waarin de kantonrechter goedkeuring onthield omdat gerekend was met de Denktank-methode. Dit zal dan al gauw om enkele honderden goedkeurende beschikkingen gaan.
}

Deze methodiek gaat uit van het gezin als een economische eenheid. In deze economische eenheid komen gelden binnen uit onder andere inkomen uit arbeid en eventuele toeslagen. Alle gelden bij elkaar wordt het nettogezinsinkomen genoemd.

Wanneer er een volwassene uit een gezin komt te overlijden, valt een aantal posten voor de overledene weg. Dit worden de Weggevallen Normatieve Uitgaven (WNU) genoemd. De WNU worden uitgedrukt in een percentage van het netto consumptieve inkomen van de economische eenheid en zijn afhankelijk van de gezinssamenstelling en de hoogte van het consumptieve gezinsinkomen.

Stap 1. Bepaal de behoefte met overlijden.

Netto besteedbaar Gezinsinkomen zonder overlijden -/Weggevallen Normatieve Uitgaven (WNU) = Gezinsbehoefte met overlijden.

Stap 2. Bepaal netto besteedbaar inkomen met overlijden.

Hierna wordt het netto besteedbaar Gezinsinkomen na overlijden bepaald. Er dient immers te worden nagegaan in hoeverre het netto besteedbaar gezinsinkomen na het overlijden in de gezinsbehoefte kan voorzien.

Stap 3. Bepaal (eventuele) weggevallen en bijkomende uitgaven.

Afhankelijk van de situatie van het betreffende gezin kan er sprake zijn van overige weggevallen uitgaven (WU), zoals een hypotheekrente die wegvalt, of bijkomende uitgaven (BU), zoals extra kinderopvang, kosten voor oppas en huishoudelijke hulp. Dit is per casus verschillend.

Stap 4. Bepaal de jaarschade.

Gezinsbehoefte met overlijden -/- Netto besteedbaar Gezinsinkomen met overlijden -/- Weggevallen uitgaven $(\mathrm{WU})+/+$ Bijkomende uitgaven $(\mathrm{BU})=($ jaar$)$ schade Gezin.

\section{Uitbreiding van de rekenmethode}

Als gezegd had de Denktank 1.0 nog een wensenlijstje liggen en kwamen er vanuit de markt ook vragen met betrekking tot uitbreiding van de rekenmethode naar niet-standaardsituaties.

Het ging daarbij om de volgende vooral rekentechnische vragen: 
1. Hoe om te gaan met de behoeftebepaling bij eenoudergezinnen?

2. Hoe om te gaan met de behoeftebepaling bij samengestelde gezinnen?

3. Hoe om te gaan met de behoeftebepaling bij co-ouderschap?

4. Kan er verduidelijking en verbetering komen van de definitie van het netto besteedbaar inkomen in de Richtlijn?

5. Hoe om te gaan met de sterftekans in het nieuwe model uit 2015? Er wordt nu helemaal geen sterftekans meegenomen. Wel bij gezinnen waar geen kinderen zijn?

Ook waren er vragen met een hoger juridisch gehalte:

6. Mogen of moeten uitkeringen worden verrekend? Kan er een deel van de opgekomen voordelen als transitievergoeding worden aangemerkt?

7. Wat te doen met een schade die alleen bij een specifieke persoon thuishoort en niet in het gezin?

8. Hoe om te gaan met hertrouwen?

\section{Opvatting Denktank: schoenmaker, blijf bij je leest}

De Denktank heeft de rekenmethode destijds ontwikkeld aan de hand van juridische kaders die min of meer vastlagen, waarbij niet zozeer de vrij casuïstische jurisprudentie, maar vooral artikel 6:108 BW zelf als uitgangspunt is genomen. Binnen dit kader is wel een duidelijk andere invulling gegeven aan de rekenmethodiek dan voorheen. Maar de Denktank had wel duidelijk de ambitie om binnen de juridische kaders te blijven, om ervoor te zorgen dat zonder aanpassing van de wet of langdurige juridische discussies (lees: procedures) partijen direct aan de slag konden met de nieuwe methode uit 2015. De Denktank 2.0 sluit aan op deze ambitie. Dit betekent onder andere dat ook de Denktank 2.0 geen standpunten inneemt als het gaat over verrekening. Daarover bestaat in de praktijk van alledag immers onvoldoende consensus. Ditzelfde geldt voor het toewijzen van bepaalde schade aan een specifieke persoon. Maatwerk is bij deze onderwerpen mogelijk (en vaak wenselijk) en kan ingepast worden in de rekenmethode, maar de juridische discussies die daaraan ten grondslag liggen, gaat de Denktank niet beslechten. Dat moeten partijen nog steeds zelf doen. Als het gaat om verdelen van schade over de nabestaanden geeft de Denktank een handvat om het te berekenen, waar overigens in paragraaf 8 nog op teruggekomen wordt, maar de Denktank laat zich niet uit over de vraag of verdeling in een individuele casus dient te geschieden of niet.

Voor wat betreft hertrouwen geldt nog iets anders. Hertrouwen zelf is al een ouderwetse term, nu veel mensen samenwonen zonder te trouwen. Betrouwbare statistieken over 'hersamenwonen' zijn er niet en het maakt bovendien voor de kans op een bestendige nieuwe relatie allicht uit of een relatie eindigt omdat partners op elkaar uitgekeken zijn of omdat een van de partners plotseling en noodlottig overlijdt. Het is dus maar de vraag of de algemene kans op het vinden van een nieu- we partner voldoende relevant is voor het antwoord op de vraag welke kans er is op het vinden van een nieuwe partner als de ander door de dood is weggerukt.

De relevantie van het al dan niet meenemen van hertrouwkansen wordt overigens soms danig overschat. Wij wijzen in dit verband op hetgeen de Hoge Raad in het arrest Bakkum/Achmea overwoog: ${ }^{2}$

'Voor een deels objectieve benadering als zojuist bedoeld bestaat te meer aanleiding omdat het hier gaat om de begroting van (grotendeels) nog niet ingetreden schade (art. 6:105 BW). Gelet op deze aard van de schadepost, maar ook om mogelijk te maken dat zo spoedig mogelijk na het ongeval in overleg tussen de aansprakelijke partij en de benadeelden een passende vergoeding voor deze vorm van gederfd levensonderhoud kan worden vastgesteld, ligt het voor de hand om bij de vaststelling van de behoefte van de kinderen aan een voorziening voor vervangende huishoudelijke hulp uit te gaan van de na het ongeval bekende concrete omstandigheden waarin zij tot aan hun meerderjarigheid zullen verkeren, en daarbij geen rekening te houden met het antwoord op de vraag of reeds daadwerkelijk is voorzien in professionele huishoudelijke hulp dan wel of de mogelijkheid bestaat dat de overblijvende ouder in de toekomst gaat trouwen of samenwonen met een nieuwe partner die huishoudelijke taken in het gezin kan gaan verrichten.'

Het antwoord op deze vraag is dus in hoge mate juridisch van aard. Voor zover het om de schade van de kinderen gaat, mag je deze in ieder geval niet de eventuele hertrouwkansen van hun overblijvende ouder tegenwerpen. Voor de schade van de overblijvende ouder zelf ligt dat wellicht anders. Wat hier verder ook van zij: de Denktank waagt zich in ieder geval niet aan (het opstellen van) een richtlijn ter zake.

$\mathrm{Na}$ eliminering van deze laatste drie meer juridische vragen 6 , 7 en 8 bleven de eerste vijf vooral rekentechnische vragen over.

\section{Eisen aan de methodiek bij de uitbreiding naar andere gezinsvormen}

Bij de uitbreiding van de methodiek moest de eenvoud van het rekenmodel uit 2015 gehandhaafd blijven en het WNUpercentage voor de desbetreffende situatie moest verdedigbaar, begrijpelijk en verklaarbaar zijn.

De grootste hobbel die genomen diende te worden, was de bepaling van de WNU en in het verlengde daarvan de behoefte in de volgende gezinssamenstellingen:

- eenoudergezinnen, waarbij de ouder overlijdt;

- samengestelde gezinnen, waarbij een volwassene overlijdt;

- co-ouderschap, waarbij een van de ouders overlijdt;

- tweeoudergezinnen, waarbij beide ouders overlijden.

2. HR 11 juli 2008, ECLI:NL:HR:2008:BC9365. 
Figuur 1 Stroomdiagram

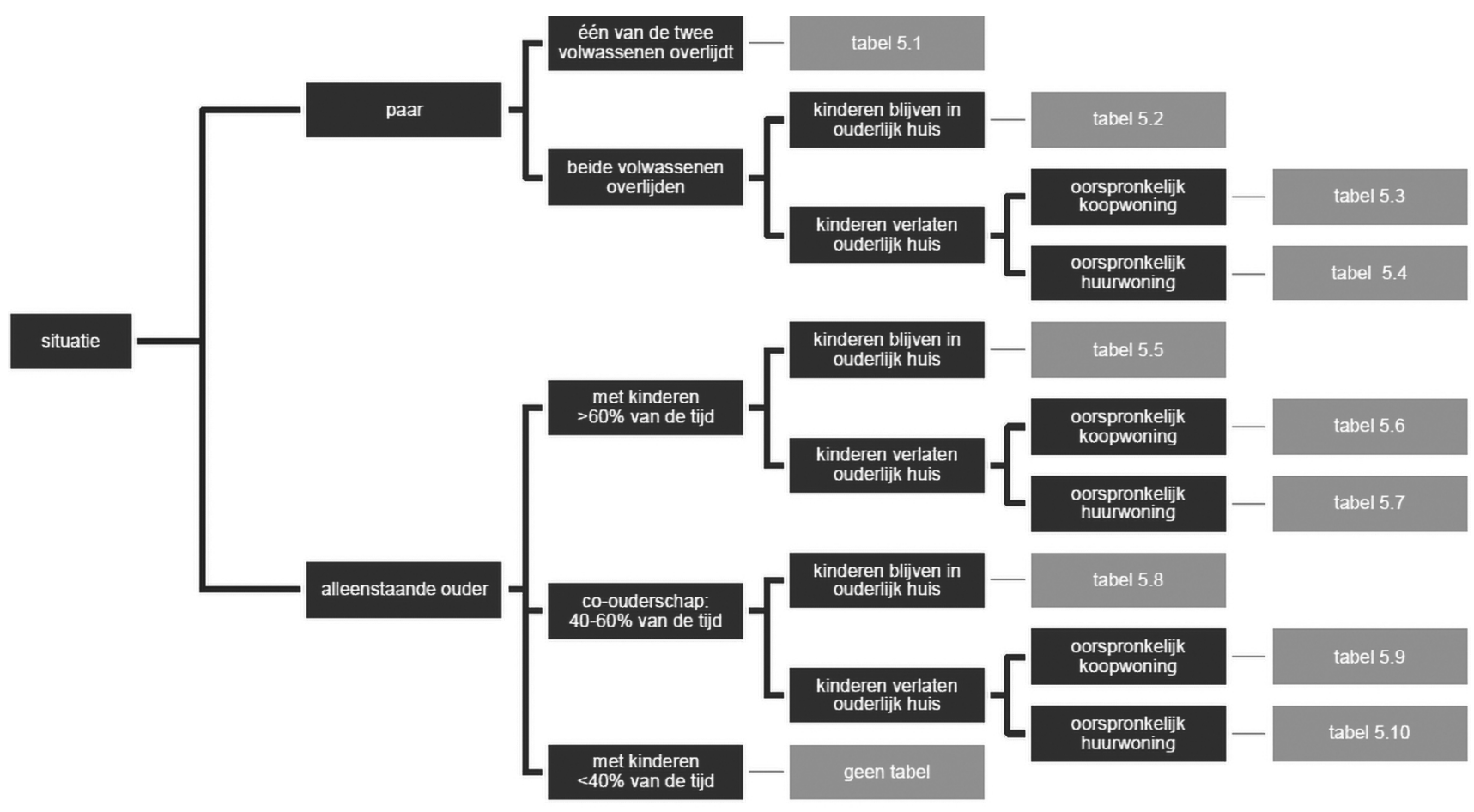

Een complicatie bij de bepaling van de WNU bij de nieuw geformuleerde gezinssituaties is dat deze afhankelijk is van de vraag of de kinderen in het ouderlijk huis blijven, of dat ze in een ander gezin opgenomen worden na het overlijden. Daarbij speelt ook de vraag of het gezin in een koopwoning of een huurwoning woonde.

Het Nibud heeft aan de hand van de gegevens waarover zij beschikt tabellen vervaardigd waar de WNU-percentages weer afhankelijk zijn van het netto besteedbaar gezinsinkomen, de gezinssamenstelling en het soort woning in de situatie voor het overlijden en de situatie van de achtergeblevenen na het overlijden.

\section{Nieuwe tabellen en een stroomdiagram}

Het Nibud vervaardigde tijdens het laatste onderzoek in totaal tien tabellen. De al bestaande tabel uit 2015 voor tweeoudergezinnen, waarbij één volwassene overlijdt, is ook direct geactualiseerd (tabel 5.1). Deze tien tabellen zijn samengevoegd in een stroomdiagram, aan de hand waarvan eenvoudig de juiste tabel kan worden gevonden voor de van toepassing zijnde situatie. Bij twijfel kunnen ook snel de mogelijke alternatieve tabellen worden gevonden en naast elkaar gelegd. Zo kan snel inzichtelijk worden gemaakt in hoeverre de alternatieven qua rekenkundige uitkomst van elkaar verschillen.

In totaal zijn er negen tabellen extra toegevoegd aan de methodiek uit 2015. Daarbij zijn voor de navolgende gezinssituaties de weggevallen normatieve uitgaven (WNU) nu ook in kaart gebracht:
- eenoudergezinnen, waarbij de ouder overlijdt;

- co-ouderschap, waarbij een van de ouders overlijdt;

- tweeoudergezinnen, waarbij beide ouders overlijden.

In dit rijtje ontbreekt dus het samengestelde gezin, de situatie waarbij het gaat om samengestelde gezinnen zal maatwerk blijven. Meestentijds zal de tabel van co-ouderschap kunnen worden toegepast, maar alertheid blijft op zijn plaats. Het gaat te ver om in dit artikel uitgebreid in te gaan op deze situatie, omdat er geen eensluidende methode is om deze situatie in kaart te brengen. Te denken valt aan de situatie dat de (overleden) ouder met de nieuwe partner ook nog een kind heeft. Dit vergt maatwerk.

In het stroomdiagram in figuur 1 zijn alle tien nu benoemde situaties te zien. Dit stroomdiagram verwijst naar de tabellen in de nieuwe versie van 2020 van De Letselschade Richtlijn Rekenmodel Overlijdensschade, die dus is uitgebreid tot tien tabellen.

\section{Berekening}

In de berekening dient speciale aandacht te worden gegeven aan de WU en BU in de nieuwe situatie na het overlijden. Denk hierbij bijvoorbeeld aan kosten die het nieuwe gezin moet maken ten behoeve van het nieuwe kind in het gezin. Deze bijkomende uitgaven (BU) zijn niet te normeren, omdat het vertrekpunt bij deze kosten niet de oorspronkelijke gezinssituatie is, maar het nieuwe gezin. Een nieuw gezin heeft ook met de extra kosten van direct levensonderhoud van het kind te maken, bijvoorbeeld voor voeding, kleding, persoonlijke 


\begin{tabular}{llll}
\hline Aantal kinderen in het gezin & totaal & per kind & ouder \\
\hline 1 & $23 \%$ & $23 \%$ & $77 \%$ \\
2 & $31 \%$ & $16 \%$ & $69 \%$ \\
3 & $37 \%$ & $12 \%$ & $63 \%$ \\
4 en meer & $42 \%$ & $11 \%$ & $58 \%$ \\
\hline
\end{tabular}

verzorging en onderwijs. Hier is echter al rekening mee gehouden bij het vaststellen van de WNU. Dit moet dan ook niet meer als BU worden aangemerkt. Het gaat bij de BU dan nog slechts om de woongerelateerde uitgaven die voor het kind extra worden gemaakt als het bij een nieuw gezin intrekt.

Zo wordt de discussie ook in dit soort zeer ingewikkelde zaken verder beperkt tot de kern, wat tijdswinst oplevert en de nabestaanden ook weer minder zal belasten dan voorheen.

\section{Verdelen}

Als er wordt gekozen voor verdeling van de schade over de nabestaanden, dan dient er onderscheid gemaakt te worden tussen het tweeoudergezin, waarbij één volwassene overlijdt en de andere soorten gezinnen. In het geval van het traditionele gezin dient er te worden verdeeld tussen de achtergebleven ouder en kinderen, waarbij op grond van de cijfers van het Nibud de volgende verdeling aangehouden wordt:

\section{- Na overlijden één ouder met kind(eren)}

\section{Zie tabel 1 .}

- Na overlijden geen ouder, wel één of meer kinderen In de gevallen dat de beide ouders overlijden, of de enige ouder overlijdt, is er uiteraard ook geen deel meer dat naar een ouder gaat. Dit deel gaat ook niet naar de eventuele nieuwe verzorgers van de kinderen. In dit soort gevallen dient er bij meerdere kinderen tussen deze kinderen gelijkelijk te worden verdeeld.

Nota bene: zowel bij A. als bij B. dient de schade per jaar te worden bepaald en verdeeld. Kinderen die vanwege hun leeftijd (meestal bij 18 of 21 jaar) geen recht meer hebben op schadevergoeding, vallen dan weg uit de schade, en natuurlijk vallen ze dan ook weg uit de verdeling daarvan.

\section{Sterftekans}

Gebleken is dat zowel de belangenbehartigers als de behandelaars aan verzekeraarszijde in de praktijk toch moeite hebben met het weglaten van een sterftekans van de achtergebleven volwassene. Om deze reden heeft de Denktank zich hier nogmaals over gebogen en is tot de volgende verwerking van de sterftekans gekomen.

\section{- Echtpaar zonder kinderen}

In de berekening van het gederfd levensonderhoud waarbij sprake is van een echtpaar zonder kinderen worden de sterftekansen van beide personen toegepast. De sterftekans van de overledene loopt vanaf het jaar van overlijden en die van de partner vanaf de datum van kapitalisatie.

\section{- Gezin met kinderen}

Daar waar er sprake is van een gezin met kind(eren) zal voor de bepaling van de looptijd van de schade zonder overlijden, het jaar van overlijden worden aangehouden om te bepalen welke levensverwachting de overledene normaal gesproken zou hebben gehad.

Zolang er nog kinderen in de berekening betrokken zijn, wordt de sterftekans van de partner (nog) niet toegepast. Zodra de kinderen uit de berekening zijn, doordat de looptijd voor hen voorbij is, zal de jaarlijkse sterftekans van de partner wel betrokken worden in de berekening. De sterftekans van de partner wordt op zijn vroegst berekend vanaf de kapitalisatiedatum.

\section{Conclusie}

Met de aanvulling op de bestaande rekenmethodiek overlijdensschade is de rekenmethodiek aanzienlijk uitgebreid en zullen de meeste zaken nu volgens deze Richtlijn opgelost en berekend kunnen worden. Natuurlijk zullen er altijd nog uitzonderingen zijn, maar de oplossing daarvan zal naar alle waarschijnlijkheid in maatwerk moeten worden gevonden.

De behoefte van het achtergebleven gezin wordt volgens de standaardmethode berekend, waarna de berekening casusspecifiek gemaakt wordt waar het gaat om het netto besteedbaar inkomen van de achtergeblevenen, door toepassing van de WU en BU.

De uitbreiding die in dit artikel is beschreven, is naar goed gebruik van de Denktank en De Letselschade Raad eerst ter consultatie voorgelegd aan de diverse relevante partijen die in het Platform van De Letselschade Raad verenigd zijn, maar ook aan partijen als de vereniging van Advocaten voor Slachtoffers van Personenschade (ASP) en de Vereniging van Letselschade Advocaten (LSA). Deze partijen hebben unaniem ingestemd met deze uitbreiding en de aanpassing van de eerdere richtlijn zoals door de Denktank voorgesteld. Daarmee is De 
Letselschade Richtlijn Rekenmodel Overlijdensschade 2020 dus een feit. ${ }^{3}$

Het blijkt toch goed mogelijk om in een wereld die, vooral ook in de pers, vaak als zeer gepolariseerd wordt omschreven, in goede harmonie en samenwerking tussen vertegenwoordigers van de slachtoffer- en verzekeraarskant tot een resultaat te komen waarin iedereen zich kan vinden. Dit mede natuurlijk door de invloed van de rekenkundigen, die als deskundige en neutrale deelnemers vooral belang hadden bij wetenschappelijk zo goed mogelijk onderbouwde waardes en uitgangspunten.

Het is ons bij de start in 2009 vooral gegaan om de nabestaanden. Instemming van de markt is dan mooi, maar de echte test zou steeds zijn of de nabestaanden ook tevreden waren. Het eerste doel was om te komen tot een methode die wél uit te leggen was. Dat is gelukt, want de berekening van de schade is sinds 2015 helder en ook duidelijk uit te leggen. Dat was voor 2015 een volstrekt ander verhaal. Natuurlijk kan er nog verschil van mening zijn over de uitgangspunten, maar dat is een discussie die nu in alle openheid wordt gevoerd. Er wordt niet langer 'onder water' aan knoppen gedraaid zonder dat de nabestaanden doorhebben wat er gebeurt. Ten slotte, en meest belangriik, is voor nabestaanden nu inzichtelijk welke schade er wordt berekend en op welke wijze. De schade die berekend wordt, komt anders dan voorheen ook overeen met de schade zoals die wordt ervaren. Nabestaanden kunnen dus ook veel beter dan voorheen inschatten of de schade die wordt vergoed ook de schade dekt zoals zij die lijden. Daarmee is een akkoord van nabestaanden met een regeling ook veel meer een echte, goed geïnformeerde instemming met het resultaat dan voorheen. Dat we dit voor de nabestaanden hebben kunnen bereiken, is voor ons van nog grotere waarde dan de instemming van de professionele marktpartijen.

Wat van groot belang is gebleken voor het succes van de nieuwe methode is dat de normering, die door gebruik van de Nibud-cijfers ontegenzeggelijk heeft plaatsgevonden, geen afbreuk heeft gedaan aan de vaststelling van de individuele schade. Die individualisering zit voor een groot deel al in de Nibud-benadering, maar vindt haar nadere uitwerking in de toepassing van de WU en BU. Normering en maatwerk blijken heel goed hand in hand te kunnen gaan.

Het werk voor de Denktank zit er nog niet helemaal op, maar met de Richtlijnen 2015 en 2020 ligt het grootste deel van het werk achter ons. Wij hopen van harte dat met deze laatste uitbreiding ook in de meer bijzondere situaties de overlijdensschades snel en in goede harmonie kunnen worden afgewikkeld.

3. De Letselschade Raad heeft de uitbreiding van de Richtlijn officieel vastgesteld en gepubliceerd op 12 maart 2020. 